\title{
Eficácia da combinação tópica de peróxido de benzoíla 5\% e clindamicina $1 \%$ para o tratamento da hipomelanose macular progressiva: um estudo randomizado, duplo-cego, placebo-controlado*
}

Efficacy of topical combination of benzoyl peroxide 5\% and clindamycin $1 \%$ for the treatment of progressive macular hypomelanosis: a randomized, doubleblind, placebo-controlled trial

Jussamara Brito Santos ${ }^{1}$ Lorena Marçal da Silva ${ }^{3}$

\author{
Olga Laura Sena Almeida ${ }^{2}$ \\ Enio Ribeiro Maynard Barreto ${ }^{4}$
}

Resumo: Fundamentos: A hipomelanose macular progressiva é uma dermatose sem etiologia definida. Não há consenso ou medicação de primeira linha para o seu tratamento e os tratamentos utilizados são pouco eficazes. OвјEтIVo: Avaliar a eficácia terapêutica da combinação tópica de peróxido de benzoíla 5\% e clindamicina 1\% associada à exposição solar para o tratamento da hipomelanose macular progressiva.

MATERIAIS E MÉTODOS: Trata-se de um estudo randomizado, duplo-cego, placebo-controlado, no qual os pacientes foram divididos em dois grupos: o Grupo A utilizou a combinação tópica de peróxido de benzoíla 5\% e clindamicina 1\% e o Grupo B usou um creme gel como placebo. Os pacientes foram orientados à exposição solar diária, avaliados e fotografados sistematicamente. Os dados coletados foram inseridos e analisados pelo software Epi Info. Definiu-se a significância estatística por valor de $p<0,05$.

Resultados: Dos 23 pacientes incluídos, 13 foram do Grupo A e 10, do Grupo B. Onze pacientes do primeiro grupo (85\%) obtiveram melhora clínica importante e apenas dois (20\%) do segundo grupo obtiveram uma melhora clínica equivalente $(p=0,003)$. Os efeitos colaterais foram mais frequentes nos pacientes do Grupo A $(p=0,003)$.

ConClusão: A combinação tópica de peróxido de benzoíla 5\% e clindamicina 1\% é eficaz no tratamento da hipomelanose macular progressiva.

Palavras-chave: Clindamicina; Dermatopatias; Peróxido de benzoíla

Abstract: BACKGROUnD: Progressive macular hypomelanosis is a dermatosis without definite etiology. There is no consensus or first-line therapy in the treatment of progressive macular hypomelanosis, and the treatment options used are very little effective.

OвJестіve: To evaluate the therapeutic efficacy of the topical combination of benzoyl peroxide $5 \%$ and clindamycin $1 \%$ associated with sun exposure for the treatment of progressive macular hypomelanosis.

MATERIALS AND METHODS: This is a randomized, double-blind, placebo-controlled study in which patients were divided into two groups. Group A used the topical combination of benzoyl peroxide 5\% and clindamycin 1\% and Group B used gel cream as a placebo. Patients were advised to expose themselves to the sun on a daily basis and were systematically evaluated and photographed. The collected data were entered and analyzed using Epi Info. A p value $<0.05$ was considered statistically significant.

RESULTS: Out of the 23 patients included in the study, 13 were in group A and 10 in group B. Eleven patients (85\%) in group A had significant clinical improvement and only two patients (20\%) in group B showed an equivalent clinical improvement $(\mathrm{p}=0.003)$. Side effects were more frequent in group $\mathrm{A}(\mathrm{p}=0.003)$.

CONCLUSION: The topical combination of benzoyl peroxide $5 \%$ and clindamycin $1 \%$ is effective in the treatment of progressive macular hypomelanosis.

Keywords: Benzoyl peroxide; Clindamycin; Skin diseases

Recebido em 26.10.2009.

Aprovado pelo Conselho Consultivo e aceito para publicação em 15.12.2010.

* Trabalho realizado no Serviço de Dermatologia do Hospital Santa Isabel - Salvador (BA), Brasil.

Conflito de interesse: Nenhum / Conflict of interest: None

Suporte financeiro / Financial funding: Serviço de Dermatologia do Hospital Santa Isabel, Salvador (BA), Brasil

Doutora; professora adjunta de Dermatologia da Escola Bahiana de Medicina e Saúde Pública (EBMSP) - Salvador (BA), Brasil.

Graduanda; acadêmica do $6^{\circ}$ ano de Medicina da Escola Bahiana de Medicina e Saúde Pública (EBMSP) - Salvador (BA), Brasil.

Mestranda; médica dermatologista do Hospital Santa Isabel - Salvador (BA), Brasil.

Mestre; professor titular de Dermatologia da Escola Bahiana de Medicina e Saúde Pública (EBMSP); chefe do Serviço de Dermatologia do Hospital Santa Isabel - Salvador (BA), Brasil. 


\section{INTRODUÇÃO}

A hipomelanose macular progressiva (HMP) é uma dermatose caracterizada por máculas numulares, hipopigmentadas, simétricas, assintomáticas, sem etiologia definida, que acometem as regiões anterior e posterior do tronco e confluem ao redor da linha média. Ocorre em todas as raças e apresenta distribuição universal, porém é mais frequente em negros ou originários de países tropicais, adultos jovens e mulheres. ${ }^{1-4} \mathrm{O}$ diagnóstico é clínico e os principais diagnósticos diferenciais são pitiríase versicolor e pitiríase alba. ${ }^{3-5}$

Guillet et al. (1988) sugeriram que a HMP é uma doença de caráter racial que acomete pessoas de raças miscigenadas. Essa hipótese se baseou na observação de achados ultraestruturais que revelaram melanossomos solitários (negroide) e melanossomos agregados (caucasoides) responsáveis por variações nas tonalidades da pele. ${ }^{2}$ A observação histológica de infiltrado linfocítico perifolicular moderado na lesão também sugere que a hipopigmentação da pele pode ser secundária a um processo inflamatório; entretanto, não há sinais clínicos de inflamação na HMP. ${ }^{1,4}$

Em 2004, Westerhof et al. propuseram que a colonização pelo Propionibacterium acnes (P. acnes) pode estar envolvida na patogenia da HMP. Esse dado resultou da observação de uma fluorescência folicular vermelha nas manchas hipopigmentadas, ausente na pele adjacente normal, ao serem iluminadas pela lâmpada de Wood em uma sala escura. A presença de cultura positiva do ducto pilossebáceo da lesão cutânea também ratificou essa hipótese. A $P$. acnes produz uma substância que interfere na produção de melanina, causando hipopigmentação da pele. ${ }^{1,4}$

Vários tratamentos para a HMP têm sido utilizados, com resultados variáveis: hidratação local, exposição solar, fototerapia, corticoides tópicos e tetraciclina via oral. ${ }^{4}$ No entanto, não há consenso ou medicação de primeira linha para essa dermatose e os tratamentos usualmente empregados têm se mostrado pouco eficazes contra a $P$. acnes,${ }^{4}$ com exceção da combinação de peróxido de benzoíla $5 \%$ e clindamicina $1 \%$. A clindamicina inibe a síntese proteica bacteriana, ligando-se à subunidade $50 \mathrm{~S}$ do ribossomo, e o peróxido de benzoíla possui radicais livres produtores de moléculas de oxigênio que reagem com a parede celular bacteriana, eliminando a $P$. acnes. Além disso, o uso combinado de peróxido de benzoíla com antibiótico tópico reduz o risco de desenvolvimento de $P$. acnes resistente. ${ }^{6}$ A eliminação da $P$. acnes com uma terapia antimicrobiana tópica poderia melhorar a repigmentação nos pacientes com HMP. ${ }^{1}$
O objetivo deste estudo foi avaliar a eficácia terapêutica da combinação tópica de peróxido de benzoíla $5 \%$ e clindamicina $1 \%$ associada à exposição solar para o tratamento da hipomelanose macular progressiva.

\section{MATERIAS E MÉTODOS}

Este estudo - previamente submetido ao Comitê de Ética em Pesquisa e devidamente aprovado - foi realizado, mediante termo de consentimento assinado por todos os pacientes, no ambulatório do Serviço de Dermatologia do Hospital Santa Izabel, Salvador (BA). Os critérios de inclusão foram: idade superior a 15 anos, diagnóstico clínico de HMP confirmado por dois médicos dermatologistas, exame micológico direto negativo e ausência de tratamento prévio há mais de 30 dias. Pacientes gestantes ou lactantes, portadores de doenças associadas e alérgicos às medicações utilizadas no estudo ou sensíveis à luz solar foram excluídos.

Trata-se de um estudo-piloto, randomizado, duplo-cego, placebo-controlado. Os pacientes foram distribuídos em dois grupos. O Grupo A recebeu a combinação tópica de peróxido de benzoíla $5 \%$ e clindamicina 1\% e o Grupo B recebeu um creme gel como placebo. O veículo utilizado nas medicações foi creme gel e idêntico nos dois grupos. As medicações formuladas foram acondicionadas em tubos iguais e denominadas A e B. A randomização foi realizada previamente por meio de uma tabela de randomização e nem os médicos, nem os pacientes tiveram conhecimento prévio sobre a alocação destes nos grupos. Os pacientes foram orientados quanto à medicação e à exposição solar diária, que devia ser de 20 minutos. As medicações foram aplicadas durante três meses. Os pacientes foram avaliados e fotografados pelos mesmos examinadores nos dias 0, 15, 60 e 90 após o início do tratamento. O critério de cura se baseou na avaliação clínica por dois examinadores e na análise das fotografias. Estabeleceuse previamente, de acordo com a área de repigmentação, a seguinte escala de melhora clínica: ausência de melhora, pouca melhora, melhora parcial, melhora importante e melhora completa.

Os dados coletados foram analisados pelo software Epi Info versão 3.5. Os testes estatísticos utilizados foram o teste de Shapiro-Wilk, para verificar se a idade e o tempo de doença dos pacientes apresentavam uma distribuição normal, o teste de KruskalWallis, para comparar se havia diferença estatisticamente significativa entre as medianas, e o teste exato de Fisher, para analisar a melhora clínica dos pacientes. Definiu-se a significância estatística por valor de $\mathrm{p}<0,05$. 


\section{RESULTADOS}

Realizou-se o estudo no período de outubro de 2008 a abril de 2009. Foram incluídos 23 pacientes, 13 no Grupo A e dez no Grupo B. Do total, 20 (87\%) eram do sexo feminino e três $(13 \%)$, do sexo masculino. As idades variaram entre 18 e 67 anos, com mediana de 25 anos e quartis de 21 e 35 anos. O tempo de doença variou entre 0,08 ano e 50 anos, com mediana de dois anos e quartis de um e sete anos. O sexo, a idade e o tempo de doença foram similares nos dois grupos (Tabela 1). Todos os pacientes avaliados tinham lesões no dorso e 16 (70\%) apresentavam, também, lesões no abdome. Regiões como mama, nádega e membros, que apresentam ocorrência menos frequente de HMP, também foram acometidas.

Todos os pacientes relataram ter feito uso regular da medicação, porém apenas sete (30\%) declararam ter feito exposição solar das lesões diariamente, quatro (57\%) do Grupo A e três (43\%) do Grupo B. Onze pacientes do primeiro grupo (85\%) obtiveram melhora importante das lesões e apenas dois (20\%) do Grupo B obtiveram uma melhora clínica equivalente, com uma diferença estatisticamente significativa entre os grupos $(p=0,003)$ (Figuras 1, 2, 3 e 4). Sete (53\%) pacientes do Grupo A apresentaram melhora completa das lesões após 90 dias do início da terapia e somente dois (20\%) do Grupo B foram curados no mesmo intervalo de tempo.

Treze (56\%) pacientes apresentaram, pelo menos, um efeito colateral durante o tratamento, onze (85\%) do Grupo A e dois (15\%) do grupo B, com uma diferença estatisticamente significativa entre os grupos $(p=0,003)$. Os efeitos colaterais clínicos relatados foram: prurido (50\%), ardência (40\%), eritema (30\%), descamação (22\%), sensação de queimação (22\%), xerodermia (8\%) e formação de placas (4\%). Esses efeitos foram bem
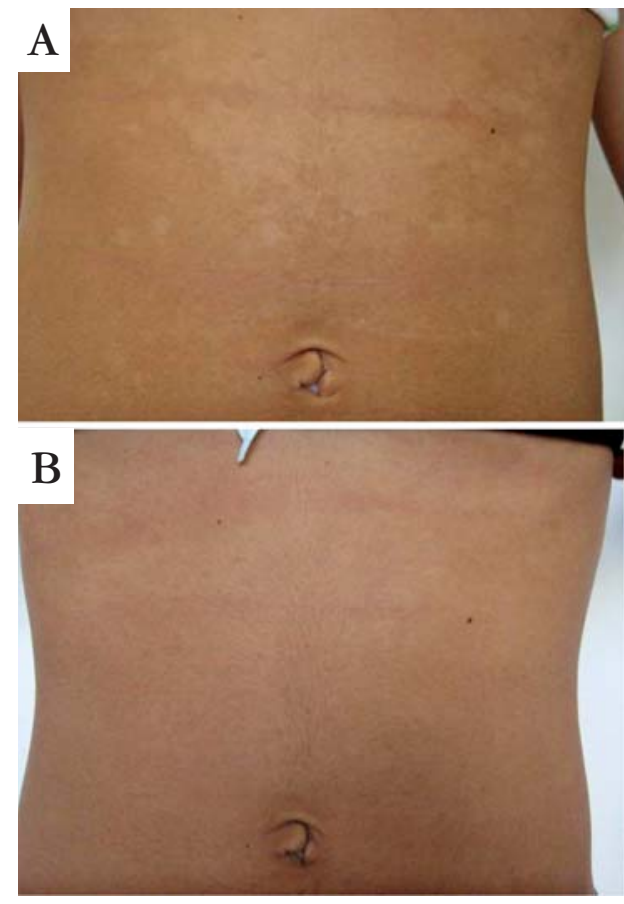

Figura 1: A Paciente do Grupo A, sexo feminino, 19 anos, antes do tratamento; B Paciente do Grupo A, sexo feminino, 19 anos, no $90^{\circ}$ dia de tratamento, com melhora importante das lesões

tolerados por todos os pacientes e não houve perda de seguimento.

\section{DISCUSSÃO}

Este estudo indica que a combinação tópica de peróxido de benzoíla $5 \%$ e clindamicina $1 \%$ melhora, significativamente, a hipopigmentação da HMP. As diferenças demográficas entre os grupos não foram relevantes. Apesar da prevalência de mulheres no estudo, não há relatos, na literatura, de que o gênero tenha influência sobre a resposta ao tratamento contra a $P$. acnes. A adesão dos pacientes à exposição solar regular foi similar entre os dois grupos, o que exclui a

TABela 1: Dados demográficos dos pacientes avaliados

\begin{tabular}{llll}
\hline & Peróxido + Clindamicina & Placebo & p \\
\hline $\begin{array}{l}\text { Idade (anos) } \\
\quad \text { Mediana }\end{array}$ & $30(23-35)$ & $24(19-31)$ & $0,4^{\mathrm{a}}$ \\
$\quad$ Variação & $18-67$ & $19-37$ & \\
Sexo (\%) & & & \\
$\quad$ Masculino & 15,4 & 10 & $0,6^{\mathrm{b}}$ \\
$\quad$ Feminino & 84,6 & 90 & \\
& & & $0,1^{\mathrm{a}}$ \\
$\begin{array}{l}\text { Tempo de doença (anos) } \\
\quad \text { Mediana } \\
\quad \text { Variação }\end{array}$ & $4(1-10)$ & $1,25(0,5-2)$ & $0,08-20$ \\
\hline
\end{tabular}

\footnotetext{
${ }^{a}$ Teste de Kruskal-Wallis
}

${ }^{\mathrm{b}}$ Teste exato de Fisher 

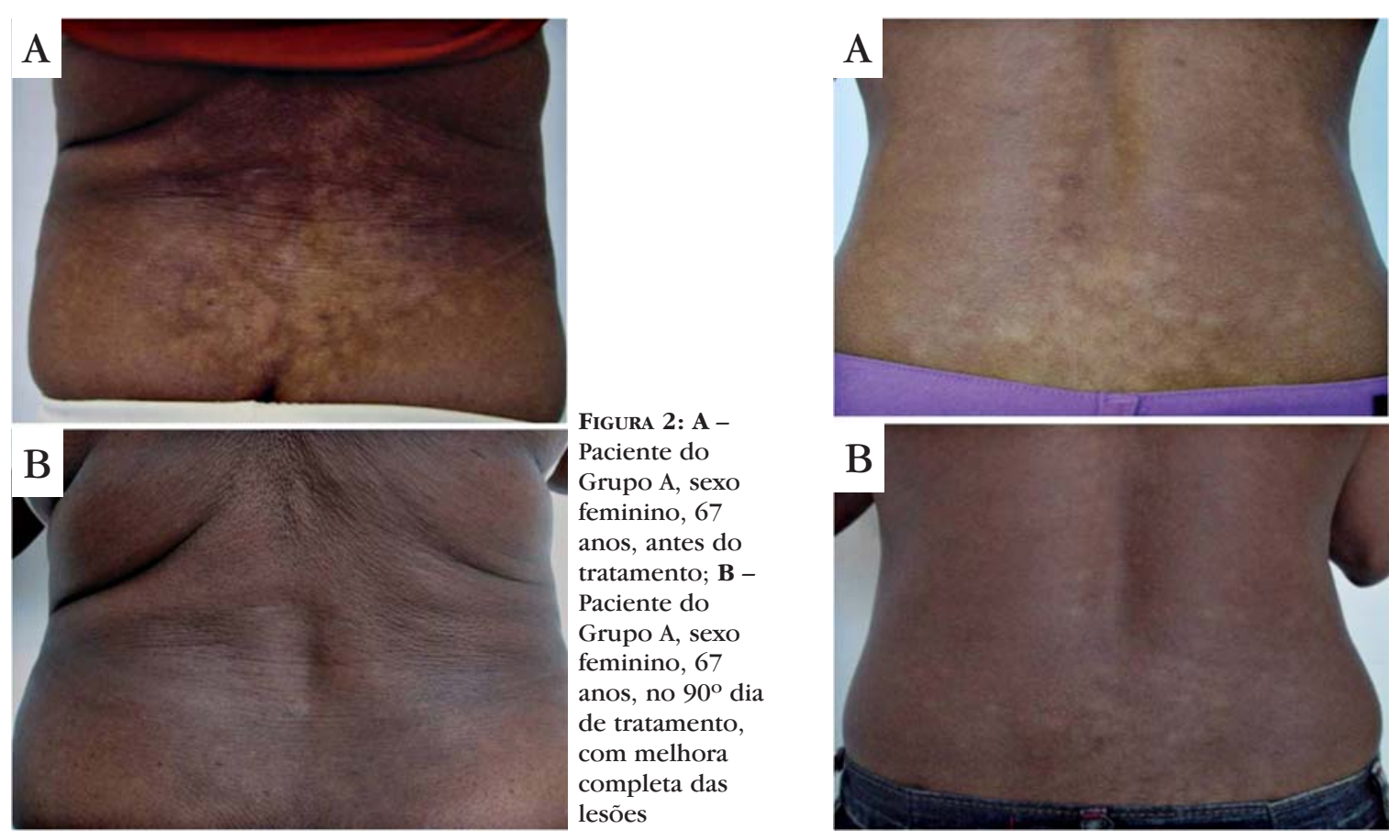

FIGURA 4: A Paciente do Grupo B, sexo feminino, 19 anos, antes do tratamento; $\mathbf{B}$ Paciente do Grupo B, sexo feminino, 19 anos, no $90^{\circ}$ dia de tratamento, com melhora parcial das lesões

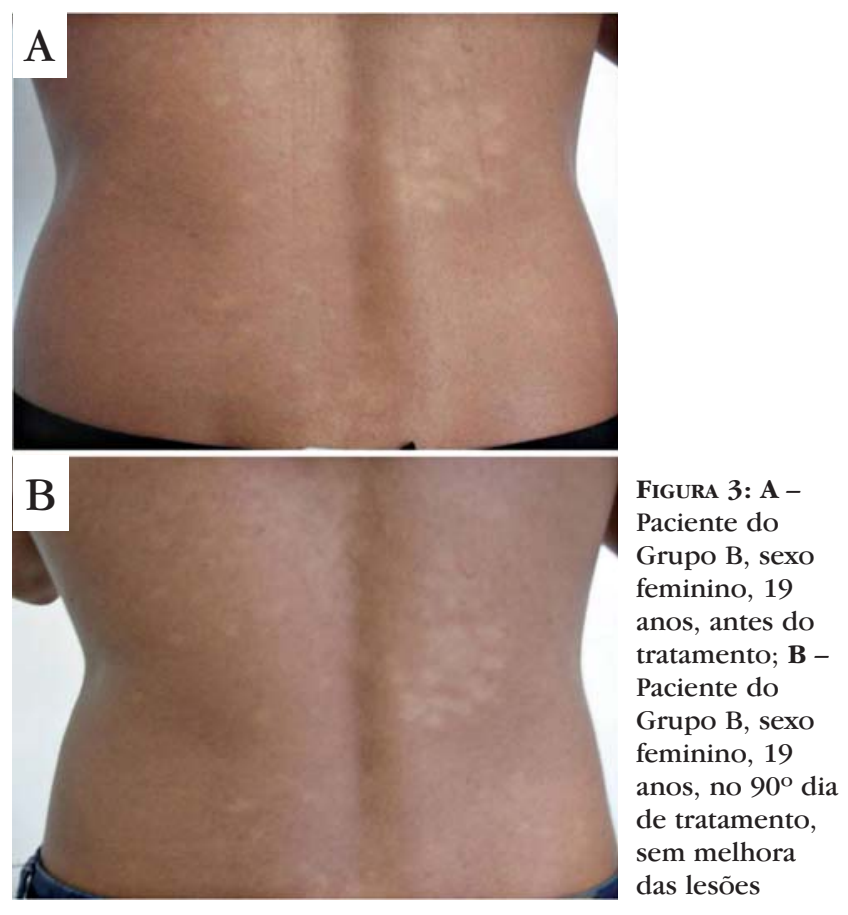

quência de efeitos colaterais ter sido significativamente maior no grupo tratado com o antimicrobiano, não houve abandono de tratamento em decorrência disso.

As principais limitações deste estudo foram o tamanho reduzido da amostra, o tempo de seguimento e a ausência de confirmação da $P$. acnes. A despeito de esta não ter sido demonstrada objetivamente nas lesões, a melhora clínica significativa do grupo tratado com peróxido de benzoíla $5 \%$ e clindamicina $1 \%$ sugere sua colonização e, ainda, sustenta a hipótese de que a colonização pela $P$. acnes possa estar envolvida na patogenia da HMP $^{1}$

Os ensaios clínicos randomizados, duplocegos e placebo-controlados são descritos como o padrão ouro na avaliação de questões terapêuticas em saúde por reduzirem a probabilidade de obtenção de dados tendenciosos na pesquisa. ${ }^{7}$ Embora a HMP seja uma dermatose hipocrômica muito frequente em nosso meio, não há estudos duplo-cegos e placebo-controlados publicados na literatura que mostrem a eficácia de agentes antimicrobianos para seu tratamento.

Ainda que a HMP não seja uma doença grave, é possibilidade de a radiação solar ser o fator responsável pelo sucesso do tratamento. É possível que a exposição solar acelere a repigmentação após o tratamento antibacteriano. ${ }^{3}$

A escolha do antimicrobiano baseou-se no fato de a combinação de peróxido de benzoíla $5 \%$ e clindamicina $1 \%$ ser bastante eficaz contra a $P$. acne ${ }^{6}$ de fácil aplicação e com poucos efeitos colaterais. ${ }^{6}$ Apesar de a freuma dermatose inestética, pouco estudada na literatura e sem um tratamento-padrão estabelecido. ${ }^{4}$ Os resultados do perfil de resposta dos pacientes tratados com a combinação tópica de peróxido de benzoíla 5\% e clindamicina $1 \%$ associada à exposição solar poderão ser utilizados na prática clínica como uma alternativa terapêutica para o tratamento da HMP. 
A perspectiva futura é avaliar prospectivamente os pacientes tratados para analisar a taxa de recidiva e o tempo de remissão decorrentes do tratamento.

\section{CONCLUSÃO}

A combinação de peróxido de benzoíla $5 \%$ e clindamicina $1 \%$ é eficaz no tratamento da HMP. Além disso, os resultados deste estudo corroboram a hipótese de que a colonização da pele por $P$. acnes pode estar envolvida na patogenia da doença.

\section{REFERÊNCIAS}

1. Westerhof W, Relyveld GN, Kingswijk M, de Man P, Menke HE. Propionibacterium acnes and the Pathogenesis of Progressive Macular hypomelanosis. Arch of Dermatol. 2004;140:210-4.

2. Guillet G, Helenon R, Gauthier Y, Surleve-Bazeille JE, Plantin P, Sassolas B. Progressive macular hypomelanosis or the trunk: primary acquired hypopigmentation. J Cutan Pathol. 1988;15:286-9.

3. Relyveld GN, Kingswijk M, Reitsma JB, Menke HS, Bos JD, Westerhof W. Benzoyl peroxide/ clindamycin/UVA is more effective than fluticasone/UVA in progressive macular hypomelanosis: A randomized study. J Am Acad Dermatol. 2006;55:836-43.

4. Relyveld GN, Menke HE, Westerhof W. Progressive macular hypomelanosis: An Overview. Am J Clin Dermatol. 2007:8:13-9.

5. Relyveld G, Menke H, Westerhof W. Progressive and extensive hypomelanosis and extensive pityriasis alba: same disease, different names? J Eur Acad Dermatol Venerol. 2005;19:370-2.

6. Silva P. Farmacologia. 7 ed. Rio de Janeiro: Guanabara Koogan, 2006.

7. Greebberg, RS; Daniels, SR; Flanders, WD; Eley, JW; Boring, JR. Epidemiologia Clínica. 3 ed. Porto Alegre: Artmed, 2005. p.30.
ENDEREÇO PARA CORRESPONDÊNCIA / MAILING ADDRESS: Jussamara Brito Santos

Rua Professor Sabino Silva, 528, Ap. 1.401

Jardim Apipema

40155-250 Salvador - BA, Brasil

Tel.: 7130177872 / 99749867

E-mail: jussamarabrito@gmail.com

Como citar este artigo/How to cite this article: Santos JB, Almeida OLS, da Silva LM, Barreto ERM. Eficácia da combinação tópica de peróxido de benzoíla 5\% e clindamicina 1\% para o tratamento da hipomelanose macular progressiva: um estudo randomizado, duplo-cego, placebo controlado. An Bras Dermatol. 2011;86(1):50-4. 